\title{
The Role of Vitamin D in Diabetes and Cardiovascular Disease: An Updated Review of the Literature
}

\author{
Dimitrios Papandreou and Zujaja-Tul-Noor Hamid \\ Department of Natural Sciences and Public Health, Zayed University, Abu Dhabi, UAE \\ Correspondence should be addressed to Dimitrios Papandreou; dimitrios.papandreou@zu.ac.ae
}

Received 21 June 2015; Revised 22 September 2015; Accepted 29 September 2015

Academic Editor: Fabrizia Bamonti

Copyright (c) 2015 D. Papandreou and Z.-T. N. Hamid. This is an open access article distributed under the Creative Commons Attribution License, which permits unrestricted use, distribution, and reproduction in any medium, provided the original work is properly cited.

\begin{abstract}
The dietary reference values for Vitamin D were set primarily considering its role in bone health, but with the discovery of Vitamin D receptors throughout body tissues, new links with other health conditions are now studied, such as for diabetes and cardiovascular diseases (CVD). This paper shall analyze and examine all new research studies carried out, especially in 2013-2015 regarding diabetes mellitus (DM) and cardiovascular diseases (CVD). Vast research has been carried out to establish strong relationship between Vitamin D serum levels, supplementation, diabetes, and CVD. However, the results from researches identified in this paper are disputable. Benefits of Vitamin D adequate levels were recognized from gestational period until later in disease development such as diabetes and/or CVD, but since not all studies are in agreement further investigation is suggested. Researches conducting large randomized controlled trials, exploring range of supplement doses, with variable baseline serum Vitamin D levels, and inclusion of array of associated parameters, are still required to conduct large-scale analysis and draw conclusion as a risk factor. Until then it is possible to conclude that maintenance of serum Vitamin D levels holds advantageous aspects in diabetic and cardiovascular conditions, and people should strive to attain them.
\end{abstract}

\section{Introduction}

Vitamin D, also called calciferol, exists in two major forms: Vitamin D2 (ergocalciferol, which is largely ingested) and Vitamin D3 (cholecalciferol, which is synthesized in human body). Both forms are inactive form, which are converted into active form, exhibiting identical responses, by two enzymatic hydroxylation reactions, first in liver forming 25 hydroxyvitamin $\mathrm{D}$ mediated by 25 -hydroxylase and second in kidney mediated by $1 \alpha$-hydroxylase forming the final activated product calcitriol (1,25 dihydroxyvitamin D). Sunshine Vitamin formerly attributed with bone health is now under rigorous investigation due to expression of Vitamin $\mathrm{D}$ receptors (VDR) found commonly in body tissues regulating gene transcription of many inflammatory factors and immune cells expression that could potentially contribute to chronic disease prognosis, recovery, or mortality [1].

Vitamin D RDA values were set for young and adult population to acquire certain serum levels of Vitamin D, which were supported by data on osteomalacia, and for older population the recommendations also considered the fracture risk. Based on Endocrine Society's recommendation, Vitamin D deficiency should be defined as 25(OH)D of $<$ $20 \mathrm{ng} / \mathrm{mL}$ while Vitamin D insufficiency is now recognized as $25(\mathrm{OH}) \mathrm{D}$ of $21-29 \mathrm{ng} / \mathrm{mL}$ [2]. The recommended dietary intake (RDI) for patients with risk for Vitamin D is $400 \mathrm{IU} / \mathrm{d}$ for $0-12$ months, $600 \mathrm{IU} / \mathrm{d}$ for ages 1-70 years, as well as for pregnant and lactating women, and $800 \mathrm{IU} / \mathrm{d}$ for ages 71 years and older, with measurement of $25(\mathrm{OH}) \mathrm{D}$ serum level as best indicator for Vitamin D cutaneous synthesis and total intake [1]. However, with concerns about sun exposure, committee assumed conditions of minimal exposure to sunlight to describe relationship between intake and serum $25(\mathrm{OH}) \mathrm{D}$ levels; therefore, it requires adjustment of values to populations exposure to sun. The potential contribution from body stores in their report is still uncertain [1].

Cutaneous synthesis of Vitamin D is subject to a number of limitations, as excess exposure can lead to photodegradation to avoid toxicity, or other factors, such as latitude, time of exposure, skin pigmentation, obesity, and season, can all 
affect the synthesis [1]. To explain the effect of latitude on T1DM, study linking them has been carried out too recently [3]. Reasons that can attenuate endogenous production of Vitamin D through skin are generally lifestyle factors, such as air pollution, confined outdoor time, completely covering body during limited exposure time, and use of sunscreen [4]. In Korean adults, these factors further included older age, male sex, eating breakfast regularly, consumption of dairy and fatty fish, and use of Vitamin D-containing supplements in a positive correlation, whereas frequent consumption of instant noodles and sugar-sweetened beverages was linked negatively [5]. Among nonmodifiable factors are skin conditions as ichthyosis [3], and variants near genes involved in cholesterol synthesis (DHCR7), hydroxylation (CYP2R1, CYP24A1), and Vitamin D transport (GC) [6].

The central function of Vitamin D is elevation of plasma calcium and phosphate levels for bone health. However, Vitamin D receptors (VDR) are also found in nucleus of many tissues, which regulate several hundred genes throughout the body or as much as $5 \%$ of human genome [1]. Biological role of Vitamin D is plausible, as evidence from recent research in the following text shall point out relationship between insulin action and Vitamin D serum levels. The fostering mechanism could be either direct, that is, when VDR expression affects local production of $1,25(\mathrm{OH})_{2} \mathrm{D}_{3}$ in pancreatic $\beta$ cells, or indirect via regulation of calcium homeostasis and calcium flux through membranes [7]. Positive effects of Vitamin D supplementation are also registered in some cases, which has further invigorated the need to investigate not only serum Vitamin D adequacy, but also the efficacy of supplements in acquiring such levels [8]. The other major investigation regarding role of Vitamin D is in development of cardiovascular diseases. Vitamin D deficiency has been found to contribute to various cardiac conditions, such as hypertension, coronary artery disease, stroke, and atherosclerosis [9-11]. Some studies consider evidence as enough to establish low Vitamin D level as CVD risk factor [12,13], but further trials are still needed. Thus, this paper shall also identify the latest research and analysis carried out linked to serum Vitamin D levels or supplementation in cardiovascular diseases.

\section{Vitamin D and Diabetes}

Abundance of Vitamin D receptors in body tissue other than just in bone deviated attention from bone disease to chronic conditions. Clinical trials were performed extensively at different levels of diabetes mellitus stages to observe the role of Vitamin D status and to study efficacy of Vitamin D supplementation. Maintaining Vitamin D at adequate levels can be a useful preventive technique, since Vitamin D status in healthy adults was inversely associated with future risk of type 2 diabetes [14]. Significant negative correlation between $25(\mathrm{OH}) \mathrm{D}$ and HbAlc was also observed when compared between diabetic and nondiabetic patients [15]. Vitamin D dose in initial years of life is shown to reduce risk of future development of disease modulated by immune protective effects [16].

A metastudy by Forouhi et al. [17] found a strong inverse association between baseline $25(\mathrm{OH}) \mathrm{D}$ and incidence of type
2 diabetes. Vitamin D supplementation also improves HbAlc value for pediatrics with type 1 diabetes when treated with 300,000 IU single dose intramuscular injection of Vitamin D along with $40 \mathrm{mg} / \mathrm{Kg} /$ day of calcium divided into 2 doses [8]. A significant inverse relationship between Vitamin D status and insulin resistance (IR) was also observed, independent of adiposity, in Korean adolescents [18]. A recent meta-analysis that included 23 studies found that serum $25(\mathrm{OH}) \mathrm{D}$ was significantly lower in patients with type $1 \mathrm{DM}$ than in healthy controls $[19,20]$. On the other hand, not all studies support the result [21], along with limitation of another review study, it was concluded from the assessment of 17 randomized control trials and 7 longitudinal studies that Vitamin D supplementation did not improve hyperglycemia, beta cell secretion, or insulin sensitivity [22].

2.1. Supplementation Studies on Vitamin D. The review study that included 17 randomized control trials mentioned above had many limitations as most studies used daily doses less than $2000 \mathrm{IU}$ to above $5000 \mathrm{IU}$ of Vitamin D2 or D3. The most important limitations were the small sample groups and heterogeneity in ethnicity and baseline levels [22]. This surely highlights the need of large randomized control trials with long-term follow-up tests. Race and gender differences were also observed as far as serum Vitamin D levels and its effect in diabetes are concerned. Low $25(\mathrm{OH}) \mathrm{D}$ concentrations were found to be associated with diabetes among White but not Black people for which variation in SNP (Single Nucleotide Polymorphism) in genotype linked with either high or low Vitamin D binding protein was held accountable [23]. In newly diagnosed type 2 diabetes female patients serum $25(\mathrm{OH}) \mathrm{D}$ is associated with insulin sensitivity and $\beta$ cell function, but this association was ambiguous in males [24].

Significant influence was not observed on weight, fat mass, or waist circumference in a randomized double blind clinical trial with Vitamin D3 supplementation of $6000 \mathrm{IU}$ of Vitamin D3/d (3 months) followed by $3000 \mathrm{IU} / \mathrm{d}$ in experimental group, and $2200 \mathrm{IU} / \mathrm{d}$ for follow-up in 6 months for both experimental and placebo groups in a recent study on type 2 diabetic obese UAE national patients [25]. Another study reported improvement in Vitamin D status and increased insulin secretion, but not insulin resistance, blood pressure, inflammation, or HbAlc in double blind randomized trial with 16 subjects in which 8 patients received $280 \mu \mathrm{g}$ daily for 2 weeks, $140 \mu \mathrm{g}$ daily for 10 weeks of colecalciferol [26]. A study by Heshmat et al. [27] carried out with 42 diabetic patients found no relationship between Vitamin $\mathrm{D}$ supplement and change in diabetes status (when observed for 3 months) with administration of single intramuscular injection of 300,000 IU of Vitamin D3, but Kuchay et al. [28] showed positive benefits of Vitamin D supplementation for 1 year on fasting plasma glucose, 2-h plasma glucose, and A1C levels with 137 subjects randomized to receive 60,000 IU for 4 weeks followed by 60,000 IU monthly of cholecalciferol. Type of Vitamin D supplement in effectiveness of supplementation was also noticed in few studies [29]. A meta-analysis of randomized control trials indicated that Vitamin D3 is more 
efficacious in raising serum $25(\mathrm{OH}) \mathrm{D}$ concentrations than Vitamin D2 [29]. At this point, it can be considered that more frequent dosage is effective in achieving benefits from supplement, as studies with single dose injection and low dose did not report efficacy of drug. Further studies investigating this opinion would be of great potential in the future.

It has been reported that aggressive treatment of Vitamin D supplementation allows improvement in serum Vitamin D levels in some studies, but it does not raise $25(\mathrm{OH}) \mathrm{D}$ status to sufficient or target levels [25, 30]. 53 patients were given ergocalciferol (D2) 50,000 IU daily over 10 days (500,000 IU) followed by Calcichew D3 (calcium carbonate/cholecalciferol) BID ( 24,000 IU cholecalciferol/month); 94 patients were given cholecalciferol (D3) 40,000 IU daily over 10 days (400,000 IU) followed by calcium rich D3 BID ( 24,000 IU cholecalciferol/month), or cholecalciferol 40,000 IU daily over 10 days (400,000 IU) followed by cholecalciferol 40,000 IU monthly to 97 patients [30]. Rise in $25(\mathrm{OH}) \mathrm{D}$ status to "sufficient" levels was concluded to be inadequate in large proportions of individuals in this study [30]. Vitamin D supplementation requires longer duration trials, with variable doses, and array of characteristic variables to establish stronger stance. Trials comparing the efficacy of Vitamin D2 and that of Vitamin D3 supplement in most similar conditions studying dosage periods as well would be quite valuable.

Generally, Vitamin D levels are safe and with many health benefits associated with gestational and type 1 diabetes mellitus. Vitamin D supplementation during pregnancy is shown to have positive birth weight and length outcomes; however, there is significant need for randomized controlled trials to establish efficacy and safety of Vitamin D supplementation as concluded from meta-analysis [31, 32]. Vitamin D supplementation in early pregnancy was also shown to have inverse association with GDM (gestational diabetes mellitus) risk [33]. Supplementation in earlier life is further linked with reduced risk of type 1 diabetes, but studies to suggest association between maternal intake and type 1 diabetes in offspring are inadequate [34].

2.2. Genetic Factors of Vitamin D Related to Diabetes. Genetic factors that may affect the Vitamin D levels in body were also explored for their link with diabetes. DHCR7 encoding 7-dehydrocholesterol reductase enzyme, which converts 7dehydrocholesterol to cholesterol, a precursor of Vitamin D3, playing a role in endogenous production of Vitamin D was studied. Genetic variants of DHCR7 were significantly associated with increased risk of type 2 diabetes, whereas CYP2R1 was not in a Danish study with 96,423 participants genotyped [35]. Allele frequencies of 18 SNPs derived from CYP2R1, GC, and DHCR7/NADSYN1 investigated in South Asians, South-East Asians, and Arabs living in Kuwait indicated significant association between the GC (rs2282679 and rs7041), CYP2R1 (rs10741657), SNPs, and 25(OH)D levels [36]. Another European cohort (IMPROVE) based study inclusive of 3,418 individuals, of whom 929 had type 2 diabetes Single Nucleotide Polymorphisms (GC; rs2282679 and rs7041) and 7-dehydrocholesterol reductase/NAD synthetase-1 (DHCR7; rs12785878 and rs3829251), was investigated and found to have negative association with $25(\mathrm{OH}) \mathrm{D}$ levels, with differences in association significances between type 2 diabetic and nondiabetic individuals. Furthermore, rs3829251 (DHCR7) influenced progression of subclinical atherosclerosis measured in a relationship dependent on type 2 diabetes status, but independent of 25(OH)D levels [37].

Involvement of VDR in T-cells immune response to antibacterial infection, regulation of complex set of regulatory factor, and control over adverse inflammatory adaptive immunity support Vitamin D's role in decidual immunity and possibly as future immunotherapy [38-41]. Mechanism through which Vitamin D was involved was also widely studied, and specific genes and their polymorphic conditions were discovered for Vitamin D receptors genes that accounted for some degree of risk. Vitamin D downregulates NF- $\kappa$ B and its downstream inflammatory cytokines expression and upregulates PPAR- $\alpha$, acting as antagonist, promoting $\beta$-oxidation, and reducing triglycerides level. It increases the expression of CPT-1, a rate limiting enzyme in mitochondria, which allows for transport of free fatty acids into mitochondria for lipid oxidation, thus reducing lipid deposition [42]. Vitamin $\mathrm{D}$ level was negatively related with serum CRP, TNF- $\alpha$ and IL-6 levels and urinal inflammation factors in patients with type 1 diabetes as well [43]. Investigations exploring specific genes, involved in diabetes, commonly hold variable alleles of the same gene accountable for risk and complications in this disease. T and b, TaqI and BsmI alleles were suggested to be protective for developing T1DM in Koreans [44]. VDR FokI polymorphism is linked to T1DM [45], or to microvascular complication [46]. Study on VDR polymorphism for the whole gene indicated susceptibility for type 1 diabetes [47]. However, meta-analysis of studies since 1998 until 2013 concludes that individual VDR polymorphisms seemed not to be associated with T1D risk, but haplotypes contributed significantly to disease susceptibility [48]. Further recognition sites were found on ApaI and TaqI for VDR gene in Egyptian type $1 \mathrm{DM}$ patients [49]. VDR rs2228570 was also suggested as a good candidate for biomarker of diabetic retinopathy in Han Chinese T2DM patients due to the association found with the $\mathrm{T}$ allele [50]. Certain VDR genes were further investigated for 1692 children from DAISY cohort, and an association with type 1 diabetes progression and polymorphism of genes was concluded; however, large cohort studies are required to replicate such data [51]. Such link of genes is also discussed in regard to diabetic nephropathy [52], where ACR (AlbuminCreatinine Ratio) is linked with progression from prediabetes to diabetes [53]. Moreover, VDR polymorphism of functional SNP $2228570 \mathrm{C}>\mathrm{T}$ (FokI) of T allele can further influence the severity of metabolic syndrome in T2D patients amongst Egyptian population [54].

Vitamin D involvement in diabetic complications attenuation was also reported in some studies. An inverse and independent relationship between circulating 25(OH)D levels and the prevalence of microvascular complications in patients with type 2 diabetes was shown [55]. Low Vitamin D status is characteristically associated with advanced diabetic nephropathy [56]. Duration of diabetes and Vitamin $\mathrm{D}$ deficiency were independent determinants of diabetic 
retinopathy in young Japanese type 1 diabetic patients [57], but there has also been report representing no link [58]. Good status of Vitamin D could delay diabetic nephropathy [43]. Suggested mechanism is through protection of podocyte, shown in mice experiment, which determines the outcome of diabetic nephropathy, or by reducing the renal fibrosis [59, 60]. Data on supplemental use of 22-oxacalcitriol, Vitamin D receptor activator, further suggests improved bone formation due to antioxidative property of Vitamin $\mathrm{D}$ in diabetic bone disease [61]. Recently, Vitamin D is also shown to be a potential protective factor for cognitive impairment in DM patients [62]. Both hypovitaminosis D and diabetes affect cardiovascular factors and could further mediate development of CHD, as suggested by a study on 798 patients [63].

Vitamin D controls the macrophage adhesion and migration, otherwise induced by its deficiency, which is a critical factor in atherosclerosis progression [64]. Vitamin D might also pose as a factor in development of vascular problems. $25(\mathrm{OH}) \mathrm{D}$ levels were found to be lowest in T2DM patients with lower extremity arterial disease (LEAD) compared to T2DM without LEAD (keeping in consideration the study limitations) [65]. Studies registered positive effects of Vitamin D sufficiency or supplementation usually, commonly as a consequence of improved diabetic parameters. To draw strong conclusion from such data, replication is crucial, since baseline characteristic was usually dissimilar, or trials dealing with same conditions were inadequate. Even to perform meta-analytic studies, extensive research is needed to determine reliable results from latest technology. The interaction of Vitamin D receptors with body's immune and inflammatory response explained through experimentation and registered through biomedical analysis surely suggests an important role, especially when the parameters identified are associated with the most common chronic conditions. Vitamin D supplementation in initial years of life or during gestational diabetes have showed positive results, but due to inadequate controlled trials carried out, further experimentation considering range of BMI, age, Vitamin D dose, duration, and so forth is imperative to draw clear line for dose efficacy and necessity. In adults much stronger influences need to be controlled, especially when Vitamin D plays a role in immunity, and adults have more developed immune system. Vitamin D supplementation usually improved the serum levels, but to attain target levels proved to be difficult; furthermore, since BMI could also play significant role, to establish specific dose in different conditions and over different anthropometric variables requires many trials tending to large and statistically significant data. However, the general approach that can be concluded with current results is that Vitamin D status in sufficient range holds no harm. Vitamin D consumption within normal range is considered beneficial. A summary of studies is presented in Table 1.

\section{Vitamin D and CVD}

Involvement of Vitamin D in numerous imperative metabolic pathways has been found to mediate health benefits by reducing risk through its effect on confounders in cardiovascular disease (CVD). The current trials and evidence are not adequate to establish causative link between Vitamin D deficiency and mortality from CVD [66], but it is shown in a systematic review and meta-analysis that Vitamin D3 supplementation does reduce overall mortality in older adults; however, further investigation regarding optimal dose and duration is necessary [67]. Studies on Vitamin D3 supplements, which were included in the meta-analysis, received supplementation ranging from 10 to $6000 \mathrm{IU} / \mathrm{d}$ (common administration form was tablets), and Vitamin D2 research received 208 to $4500 \mathrm{IU} / \mathrm{d}$ with not much heterogeneity to be observed with Vitamin D3. As regards Vitamin D2 supplementation, increased risks of mortality were found with lower intervention doses and shorter average intervention periods [67]. Vitamin D deficiency and mortality from CVD could not be linked as causal, possibly because Vitamin D deficiency could be a consequence of CVD leading to low plasma $25(\mathrm{OH}) \mathrm{D}$ other than being the cause of CVD [68]. This can be summarized by "resilience factor hypothesis," which suggests that Vitamin D deficiency could be an indirect risk factor, causing fatal outcomes of the disease linked by immunosuppressive effects and inflammatory markers, rather than being direct cause of fatality [66]. In a study including 7746 US adults, Vitamin D deficiency was associated with mortality from chronic obstructive pulmonary disease (COPD) [69]. The association between Vitamin D status and COPD observed could be because COPD patients develop a low Vitamin D status as a consequence of the disease rather than Vitamin D status affecting the development and progression of the disease (as persons with COPD are more prone to Vitamin D deficiency for several reasons: the physical impairment leads to reduced outdoor activity, old age which is associated with low Vitamin status, etc.) [70]. Hence, the crucial dilemma is whether Vitamin D fosters immune response in fatal course, or if immune system fosters Vitamin D deficiency during fatal course.

Biochemical processes are further explored to assess the pathway to expand on the dilemma faced regarding the fatal course of disease. The suggested mechanism through which Vitamin D contributes to cardiovascular health is by suppressing genes involved in producing renin, thus downregulating the RAA system [71]. Hypovitaminosis of Vitamin D induces calcium deposition in vessels and soft tissues, which may also activate RAA system [71]. Vitamin $\mathrm{D}$ receptors involvement in inflammation further facilitates reduction of atherogenesis by downregulating proinflammatory factors and upregulating anti-inflammatory factors, thus preserving the endothelial function of vascular muscle cells $[71,72]$. Other confounders of this chronic condition are also under influence of Vitamin D, such as metabolic syndrome, hypertension, hyperglycemia, hyperlipidemia, insulin resistance, and obesity for which Vitamin D is shown to be beneficial, as reviewed in $[73,74]$.

Results support causal effect of higher Vitamin D status on a more favorable lipid profile [75] and decreased incidence of metabolic syndrome [76], but more studies are required to establish proper causative link. Thus, mechanisms are suggested and supporting values are provided; however, science is always about experimenting and needs continuous testing to explain further. Beneficial HDL cholesterol, triglycerides, 


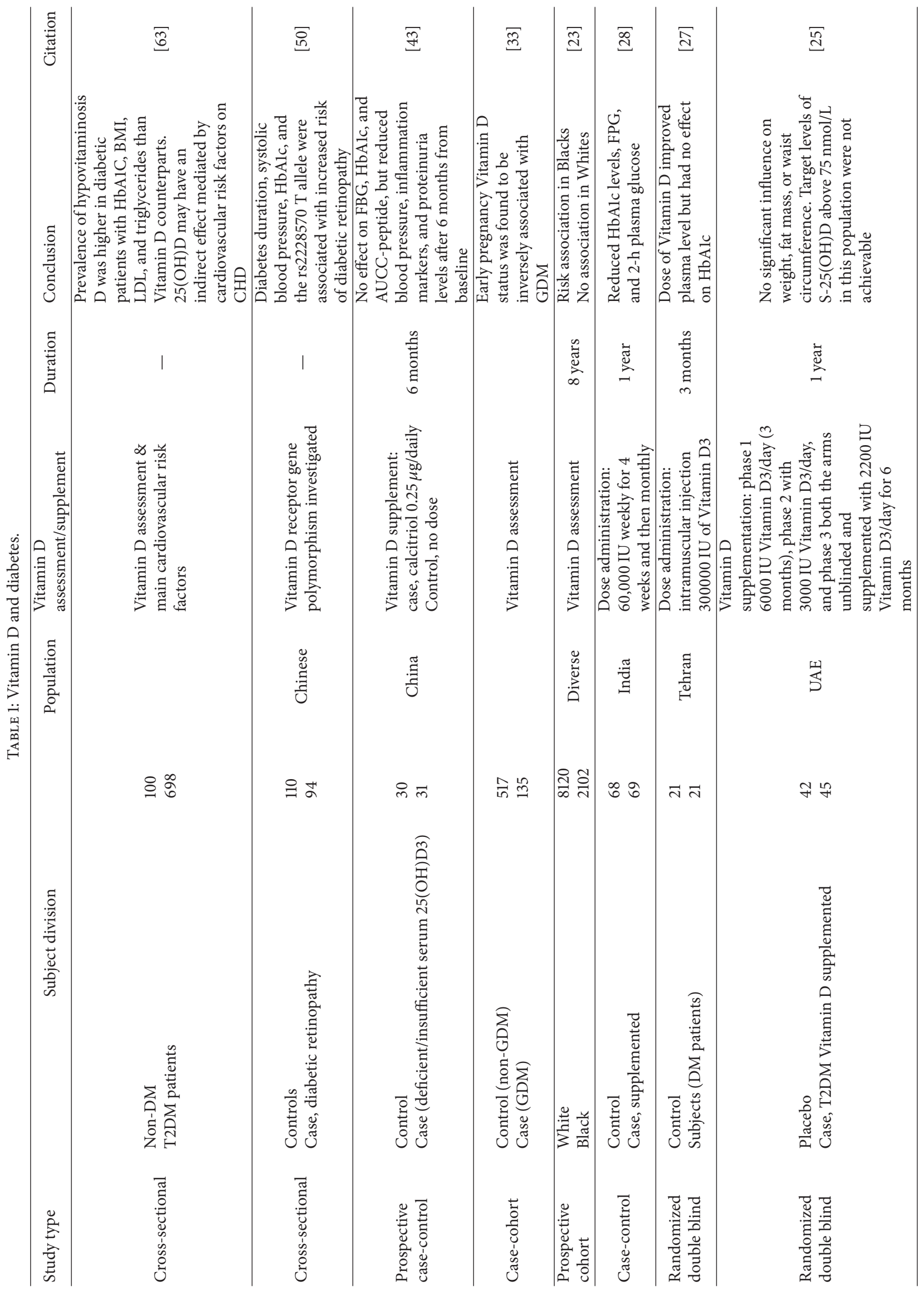




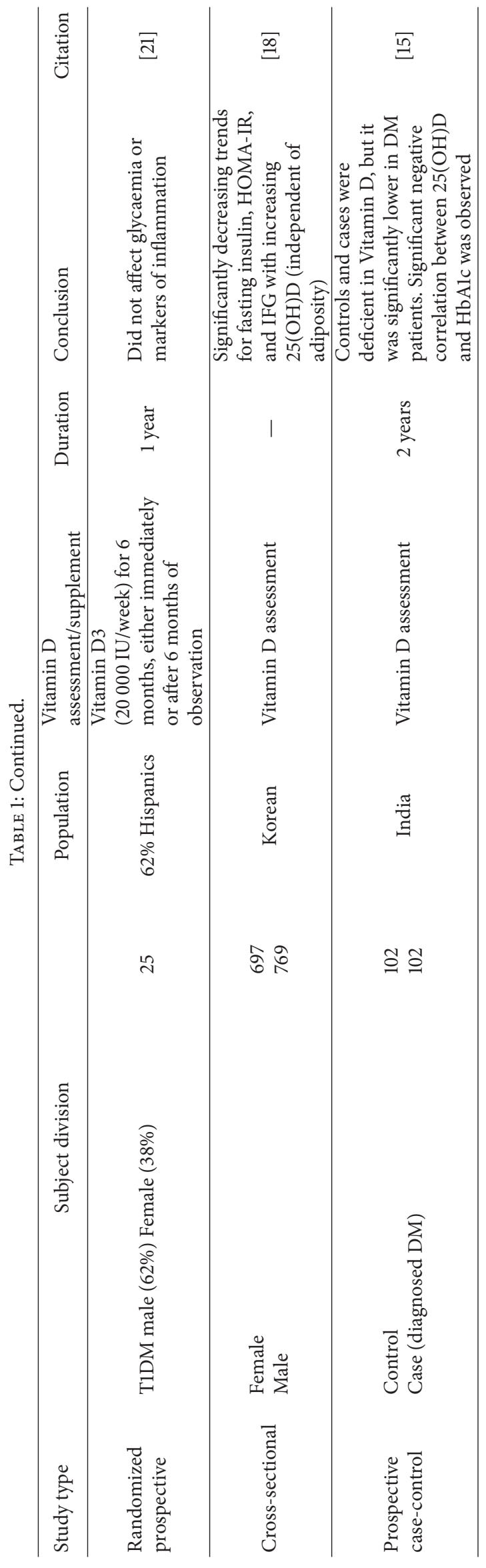


waist circumference, serum glucose, and low prevalence of metabolic syndrome were observed with higher Vitamin D concentration $[77,78]$.

Vitamin D supplementation might improve mortality in chronic kidney disease patients, since a study reports insulin resistance and Vitamin D deficiency as independent predictors of left ventricular hypertrophy and atherosclerosis [79]. Low 25(OH)D levels were also found to be associated with reduced incidence of CVD, much significantly for fatal cases [80]. A meta-analysis of the most well controlled randomized human trial data available however does not show benefit of Vitamin D on CVD, although small studies indicate benefits [81].

Vitamin D status was also found to have no role in the etiology of Atrial Fibrillation [82]. But augmentation index, to measure arterial stiffness, was reduced [83] in patients when supplemented (119 deficient patients randomized to receive either 50,000 international units (IU) or 100,000 IU single intramuscular Vitamin D3) and so did other mediators of arterial stiffness (62 participants received cholecalciferol 2,000 IU/day + calcium $200 \mathrm{mg} /$ day, or the placebo with calcium $200 \mathrm{mg} / \mathrm{day}$ ) [84]. In diabetic patients it did not show any benefits [85].

Evidence for association between Vitamin D status and ischemic stroke still remains equivocal. No association between Vitamin D status and incidence of stroke was found in some studies $[86,87]$, but low $25(\mathrm{OH}) \mathrm{D}$ levels as risk factor for stroke, specifically for those predisposed to high D binding protein, who thus have low bioavailability of Vitamin $\mathrm{D}$, were also presented as hypothesis in one experiment with supporting outcome [10]. In Indian subjects Vitamin $\mathrm{D}$ deficiency was also associated with acute myocardial infarction (MI) [88]. Racial disparity was observed in heart failure cases for Vitamin D deficient patients [89]. In some conditions, such as MI, stroke, and arterial stiffness, data from recently performed experiments is not adequate to conclude, and it shall be valuable to continue recording with latest technology.

Data on blood pressure is still indecisive. In Mendelian analysis it was concluded that increased Vitamin D levels could reduce hypertension risk, but further replication of study is necessary [90]. Vitamin D supplementation for hypertensive, low Vitamin serum levels subjects did not improve their blood pressure when given either $2800 \mathrm{IU}$ of Vitamin D3 per day as oily drops $(n=100)$ or placebo ( $n=100)$ for 8 weeks [91]; further controlled trial is on the way to assess the link [92]. In a review conducted on Vitamin D supplementation trials, the result was inconclusive, since randomized trials with higher Vitamin D dose are potentially required to realize specific outcome [93]. Through Mendelian randomization analysis, a causal effect of Vitamin D deficiency on increased blood pressure was suggested [94]. Studies need to be replicated in an independent, similarly powered study, as some inconsistencies were present that could be attributed to the baseline differences in $25(\mathrm{OH}) \mathrm{D}$ concentrations or blood pressure, or other sources of heterogeneity between the studies.
3.1. Supplementation Studies on Vitamin D. Vitamin D supplementation effects were investigated too, commonly to improve serum levels and to study the effect it had for target identified in research studies. Vitamin D supplementation in deficient people, free of cardiovascular risk, improved myocardial deformation parameters and epicardial fat thickness; moreover, link between Vitamin D levels and impaired left ventricular global longitudinal strain was suggested [95]. Vitamin D replacements in type 2 diabetic patients potentially have beneficial effects on cardiovascular disease risk factors too, as indicated by research on 119 type 2 diabetic patients given calcitriol 0.5 micrograms per day for 8 weeks [96]. Vitamin D deficiency is also shown through one study, to play a role in hypertension [97]. Vitamin D supplementation could aid control of systolic blood pressure, diastolic blood pressure, and mean arterial blood pressure, as concluded from study with 42 outpatients with elevated blood pressure given one capsule containing $50000 \mathrm{IU}$ of cholecalciferol weekly in intervention group [98]. Endothelial function might be impaired in healthy but Vitamin D deficient young women, which is shown to improve with 6-month replacement therapy, possibly due to immune-modulatory effects [99]. Vitamin D might also influence efficacy of drugs, as finding from study on children with lupus assessing effect of atorvastatin on carotid IMT progression reflects that serum $25(\mathrm{OH}) \mathrm{D}$ level $\geq 20 \mathrm{ng} / \mathrm{mL}$ had less carotid IMT progression from treatment [100].

\subsection{Vitamin D's Relation to Cardiovascular Inflammatory}

Conditions. CVD development and progression commonly involve atherosclerosis buildup and narrowed vessels; the following trials shall indicate the link between these conditions and Vitamin D serum status. Vitamin D deficiency may lead to coronary atherosclerosis, and plaque buildup, but study does not define relationship with the composition [101]. Meta-analysis conducted for research published on "PubMed" from 2009 onwards does not conclude beneficial effect of Vitamin D on vascular reactivity [102]. To study presence of calcific atherosclerosis or obstructive coronary artery stenosis with low Vitamin D, study inclusive of 1131 individuals was conducted; however, no association was found [103]. In 375 patients undergoing coronary angiography, Vitamin $\mathrm{D}$ was the most significant predictor found for coronary artery disease measured by $>50 \%$ stenosis in each major coronary artery [104]. To conclude link between Vitamin D levels and coronary atherosclerosis measured by coronary artery calcium, evidence is insufficient and needs further large sample studies with proper Vitamin D assessment levels and confounders adjustment (reviewed in [105]). Carotid intima media thickness (CIMT) and arterial stiffness were not associated with Vitamin D deficiency in patients with type 2 diabetes [106], with systemic lupus erythematosus [107, 108], nondiabetic males with HIV [109], amongst juvenile and adult [110], with primary hyperparathyroidism [111], or random patients admitted to internal medicine [112]. On the other hand, serum Vitamin D level was significantly, independently associated with carotid atherosclerosis in type 2 diabetes patients, since CIMT levels and proportion of 


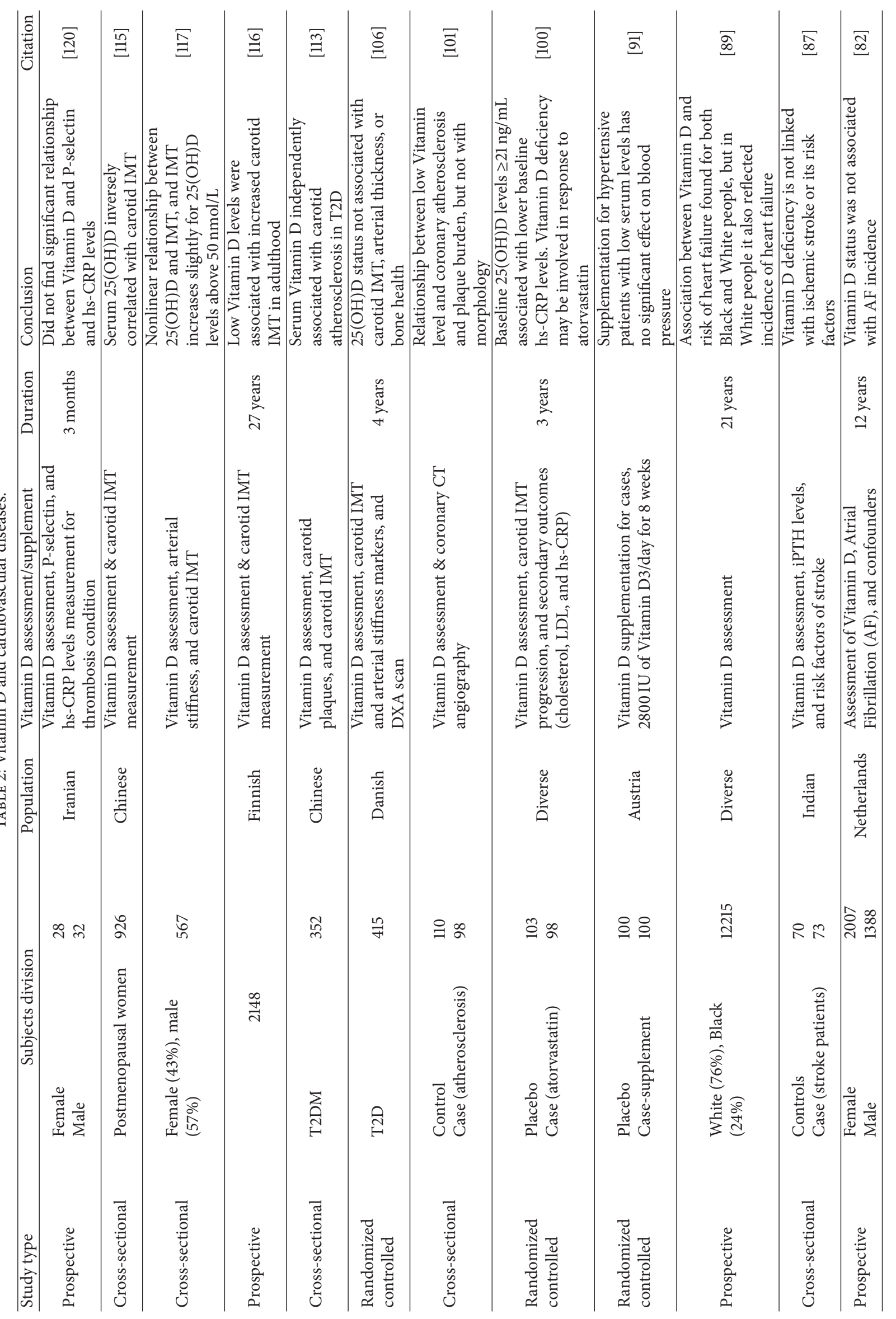




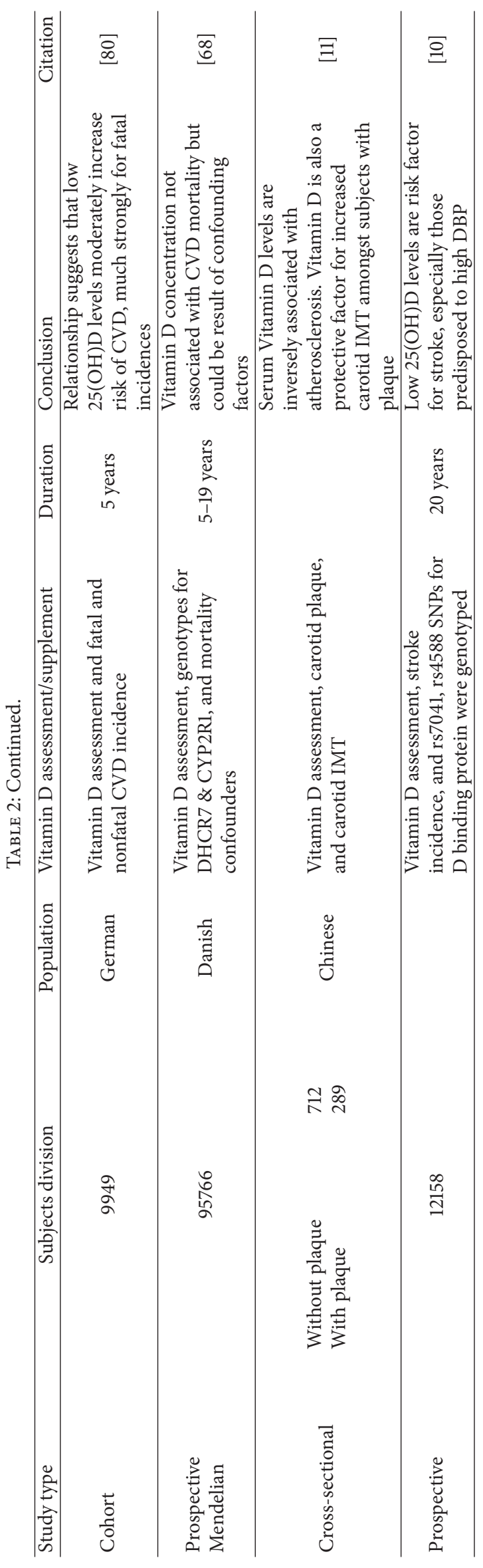


carotid plaques were higher in lowest quartile of $25(\mathrm{OH}) \mathrm{D}$ than in the highest quartile [113], or in psoriasis patients with increased risk of carotid atherosclerosis, especially those with a longer history of psoriasis [114], while the first published study on healthy postmenopausal Chinese women investigating CIMT and Vitamin D also found a similar inverse relationship [115]. Low 25(OH)D level in childhood was shown to have increased risk for carotid IMT in adulthood [116]. Study investigating relationship between higher Vitamin D levels and cardiovascular risk also reports from its 567 subjects that serum levels of $50 \mathrm{nmol} / \mathrm{L}$ and above show slight increase in IMT with increasing $25(\mathrm{OH}) \mathrm{D}$ levels [117]. Hypovitaminosis D might further be involved in thoracic atherosclerosis pathogenesis too, as lower $25(\mathrm{OH}) \mathrm{D}$ was independently associated with higher aortic IMT [118]. Studies on thromboembolism do not provide conclusive result and lack large group trials; results of studies focusing on P-selectin or hs-CRP are nonsupportive [119, 120], even when considering it as risk factor to disease [121]. However, significant inverse relationship between serum 25(OH)D level and hs-CRP levels (inflammatory marker) was also detected, and it is this inflammatory process throughout the disease which plays a role in its progression [98]. Insulinlike growth factor-1 (IGF-1), which evidentially counteracts vascular aging, circulates in blood when Vitamin D levels are low, according to Baltimore Longitudinal Study of Aging (BLSA) including 472 participants [122].

\subsection{Genetic Factors of Vitamin D Related to Cardiovascular} Diseases. Genetic factors that contribute to Vitamin D status of body were also investigated for their role in cardiovascular diseases. Single Nucleotide Polymorphisms (SNPs) in GC and DHCR7 were associated with serum levels of 25(OH)D levels, and only rs3829251 (DHCR7) influenced progression of subclinical atherosclerosis [37]. In another study inclusive of 535 individuals SNPs of CYP1A1 and CYP1B1 were identified and indicated synergistic effect on blood pressure [123]. Sixtythree male patients recruited with coronary artery disease (CAD) were genotyped for both the rs12785878 (NADSYN1) polymorphism and the rs1790349 (DHCR7). Data backs the investigated SNPs ability to predict circulating $25(\mathrm{OH}) \mathrm{D}$ levels but opposes their use as genetic markers for CAD [124]. Future studies addressing the interaction could be insightful for prevention and treatment. Many trials recognize low serum levels of Vitamin D to impact cardiovascular health negatively, whereas some still do not support, and so continuous experimentation expanding on vast range of confounders is suggestive to draw conclusion. A summary of studies is presented in Table 2 .

\section{Conclusion}

This paper generally looked at researches or reviews conducted mostly during 2013 and mid-2015. Majority of results put forth suggest beneficial associations between Vitamin D, diabetic conditions, and cardiovascular diseases. And, the mechanisms defined propose maintenance of Vitamin $\mathrm{D}$ levels in desired range to prevent, delay, or control diabetes. Serum Vitamin D levels also improved cardiovascular function. All benefits of Vitamin D are concentrated in the role of this molecule in inflammation, immunity, and gene transcription. Use of supplement also proved to be beneficial, but to the extent of acquiring proper serum levels. To establish specific recommendation regarding their use still demands insight into the administered doses and duration, as in some studies Vitamin D supplementation doses were high, but for short time, whereas in others they were administered for few months in small doses. Thus, maintaining adequate Vitamin D levels is vital for chronic condition prevention, severity, and improvement.

Conclusive recommendation is that further trials are necessary to establish causal risk association. Many aspects of CVD, such as stroke, blood pressure, atrial stiffness, carotid intima, and media thickness, provide equivocal results. It is imperative to continue with large, long-term controlled trials, including range of disease confounders and properly identified baseline data to reach final stance. Further studies are required to establish causality, minimize population based genetic variance, harmonize baseline Vitamin D levels, and target specific groups. Prospective study considering changing Vitamin D levels year-round would eliminate certain limitations associated with study type reported in some cases.

\section{Conflict of Interests}

The authors declare that there is no conflict of interests regarding the publication of this paper.

\section{References}

[1] A. C. Ross, C. L. Taylor, A. L. Yaktine, and H. B. Del Valle, Dietary Reference Intakes for Calcium and Vitamin D, National Academies Press, Washington, DC, USA, 2011.

[2] M. F. Holick, "Vitamin D status: measurement, interpretation, and clinical application," Annals of Epidemiology, vol. 19, no. 2, pp. 73-78, 2009.

[3] S. J. Ball, A. Haynes, P. Jacoby et al., "Spatial and temporal variation in type 1 diabetes incidence in Western Australia from 1991 to 2010: increased risk at higher latitudes and over time," Health and Place, vol. 28, pp. 194-204, 2014.

[4] D. Papandreou, P. Malindretos, Z. Karabouta, and I. Rousso, "Possible health implications and low vitamin D status during childhood and adolescence: an updated mini review," International Journal of Endocrinology, vol. 2010, Article ID 472173, 7 pages, 2010.

[5] H. K. Joh, C. S. Lim, and B. Cho, "Lifestyle and dietary factors associated with serum 25-hydroxyvitamin D levels in Korean young adults," Journal of Korean Medical Science, vol. 30, no. 8, pp. 1110-1120, 2015.

[6] T. J. Wang, F. Zhang, J. B. Richards et al., "Common genetic determinants of vitamin $\mathrm{D}$ insufficiency: a genome-wide association study," The Lancet, vol. 376, no. 9736, pp. 180-188, 2010.

[7] S. Christakos, M. Hewison, D. G. Gardner et al., "Vitamin D: beyond bone," Annals of the New York Academy of Sciences, vol. 1287, no. 1, pp. 45-58, 2013.

[8] S. Mohammadian, N. Fatahi, H. Zaeri, and M. A. Vakili, "Effect of vitamin D3 supplement in glycemic control of pediatrics with type 1 diabetes mellitus and vitamin D deficiency," Journal of 
Clinical and Diagnostic Research, vol. 9, no. 3, pp. SC05-SC07, 2015.

[9] C. Wang, "Role of vitamin D in cardiometabolic diseases," Journal of Diabetes Research, vol. 2013, Article ID 243934, 10 pages, 2013.

[10] L. Schneider, P. L. Lutsey, E. Selvin et al., "Vitamin D, vitamin D binding protein gene polymorphisms, race and risk of incident stroke: the Atherosclerosis Risk in Communities (ARIC) study," European Journal of Neurology, vol. 22, no. 8, pp. 1220-1227, 2015.

[11] Y. Hao, X. Ma, Y. Luo et al., "Additional role of serum 25hydroxyvitamin D3 levels in atherosclerosis in Chinese middleaged and elderly men," Clinical and Experimental Pharmacology and Physiology, vol. 41, no. 3, pp. 174-179, 2014.

[12] P. G. Weyland, W. B. Grant, and J. Howie-Esquivel, "Does sufficient evidence exist to support a causal association between vitamin D status and cardiovascular disease risk? An assessment using Hill's criteria for causality," Nutrients, vol. 6, no. 9, pp. 3403-3430, 2014.

[13] K. Kienreich, A. Tomaschitz, N. Verheyen et al., "Vitamin D and cardiovascular disease," Nutrients, vol. 5, no. 8, pp. 3005-3021, 2013.

[14] H. Khan, S. Kunutsor, O. H. Franco, and R. Chowdhury, "Vitamin D, type 2 diabetes and other metabolic outcomes: a systematic review and meta-analysis of prospective studies," Proceedings of the Nutrition Society, vol. 72, no. 1, pp. 89-97, 2013.

[15] B. A. Laway, S. K. Kotwal, and Z. A. Shah, "Pattern of 25 hydroxy vitamin D status in North Indian people with newly detected type 2 diabetes: a prospective case control study," Indian Journal of Endocrinology and Metabolism, vol. 18, no. 5, pp. 726-730, 2014.

[16] C. V. Harinarayan, "Vitamin D and diabetes mellitus," Hormones, vol. 13, no. 2, pp. 163-181, 2014.

[17] N. G. Forouhi, Z. Ye, A. P. Rickard et al., "Circulating 25hydroxyvitamin $\mathrm{D}$ concentration and the risk of type 2 diabetes: results from the European Prospective Investigation into Cancer (EPIC)-Norfolk cohort and updated meta-analysis of prospective studies," Diabetologia, vol. 55, no. 8, pp. 2173-2182, 2012.

[18] S. J. Chung, Y. A. Lee, H. Hong et al., "Inverse relationship between vitamin D status and insulin resistance and the risk of impaired fasting glucose in Korean children and adolescents: the Korean National Health and Nutrition Examination Survey (KNHANES) 2009-2010," Public Health Nutrition, vol. 17, no. 4, pp. 795-802, 2014.

[19] R. Feng, Y. Li, G. Li et al., "Lower serum 25 (OH) D concentrations in type 1 diabetes: a meta-analysis," Diabetes Research and Clinical Practice, vol. 108, no. 3, pp. e71-e75, 2015.

[20] E. Serra-Planas, E. Aguilera, M. L. Granada et al., "High prevalence of vitamin D deficiency and lack of association with subclinical atherosclerosis in asymptomatic patients with Type 1 diabetes mellitus from a Mediterranean area," Acta Diabetologica, vol. 52, no. 4, pp. 773-779, 2015.

[21] E. M. Shih, S. Mittelman, P. Pitukcheewanont, C. G. Azen, and R. Monzavi, "Effects of vitamin D repletion on glycemic control and inflammatory cytokines in adolescents with type 1 diabetes," Pediatric Diabetes, 2015.

[22] N. Nigil Haroon, A. Anton, J. John, and M. Mittal, "Effect of vitamin D supplementation on glycemic control in patients with type 2 diabetes: a systematic review of interventional studies," Journal of Diabetes \& Metabolic Disorders, vol. 14, no. 1, article 3, 2015.
[23] J. P. Reis, E. D. Michos, E. Selvin, J. S. Pankow, and P. L. Lutsey, "Race, vitamin D-binding protein gene polymorphisms, 25hydroxyvitamin $\mathrm{D}$, and incident diabetes: the Atherosclerosis Risk in Communities (ARIC) Study," American Journal of Clinical Nutrition, vol. 101, no. 6, pp. 1232-1240, 2015.

[24] Y. Gao, X. Wu, Q. Fu, Y. Li, T. Yang, and W. Tang, "The relationship between serum 25-hydroxy vitamin D and insulin sensitivity and $\beta$-cell function in newly diagnosed type 2 diabetes," Journal of Diabetes Research, vol. 2015, Article ID 636891, 5 pages, 2015.

[25] A. Sadiya, S. M. Ahmed, M. Carlsson et al., "Vitamin $\mathrm{D}_{3}$ supplementation and body composition in persons with obesity and type 2 diabetes in the UAE: a randomized controlled double-blinded clinical trial," Clinical Nutrition, 2015.

[26] U. Kampmann, L. Mosekilde, C. Juhl et al., "Effects of 12 weeks high dose vitamin D3 treatment on insulin sensitivity, beta cell function, and metabolic markers in patients with type 2 diabetes and vitamin D insufficiency-a double-blind, randomized, placebo-controlled trial," Metabolism, vol. 63, no. 9, pp. 1115-1124, 2014.

[27] R. Heshmat, O. Tabatabaei-Malazy, S. Abbaszadeh-Ahranjani et al., "Effect of vitamin D on insulin resistance and anthropometric parameters in Type 2 diabetes; a randomized double-blind clinical trial," DARU Journal of Pharmaceutical Sciences, vol. 20, no. 1, article 10, 2012.

[28] M. S. Kuchay, B. A. Laway, M. I. Bashir, A. I. Wani, R. A. Misgar, and Z. A. Shah, "Effect of Vitamin D supplementation on glycemic parameters and progression of prediabetes to diabetes: a 1-year, open-label randomized study," Indian Journal of Endocrinology and Metabolism, vol. 19, no. 3, pp. 387-392, 2015.

[29] L. Tripkovic, H. Lambert, K. Hart et al., "Comparison of vitamin $D_{2}$ and vitamin $D_{3}$ supplementation in raising serum 25-hydroxyvitamin D status: a systematic review and metaanalysis," American Journal of Clinical Nutrition, vol. 95, no. 6, pp. 1357-1364, 2012.

[30] U. Alam, A. W. S. Chan, A. Buazon et al., "Differential effects of different vitamin D replacement strategies in patients with diabetes," Journal of Diabetes and Its Complications, vol. 28, no. 1, pp. 66-70, 2014.

[31] R. J. Moon, N. C. Harvey, and C. Cooper, "Endocrinology in pregnancy: influence of maternal vitamin $\mathrm{D}$ status on obstetric outcomes and the fetal skeleton," European Journal of Endocrinology, vol. 173, no. 2, pp. R69-R83, 2015.

[32] N. C. Harvey, C. Holroyd, G. Nitani et al., "Vitamin D supplementation in pregnancy: a systematic review," Health Technology of Assessment, vol. 18, no. 45, pp. 1-190, 2014.

[33] D. L. Arnold, D. A. Enquobahrie, C. Qiu et al., "Early pregnancy maternal vitamin $\mathrm{D}$ concentrations and risk of gestational diabetes mellitus," Paediatric and Perinatal Epidemiology, vol. 29, no. 3, pp. 200-210, 2015.

[34] J.-Y. Dong, W.-G. Zhang, J. J. Chen, Z.-L. Zhang, S.-F. Han, and L.-Q. Qin, "Vitamin D intake and risk of type 1 diabetes: a metaanalysis of observational studies," Nutrients, vol. 5, no. 9, pp. 3551-3562, 2013.

[35] S. Afzal, P. Brøndum-Jacobsen, S. E. Bojesen, and B. G. Nordestgaard, "Vitamin D concentration, obesity, and risk of diabetes: a mendelian randomisation study," The Lancet Diabetes and Endocrinology, vol. 2, no. 4, pp. 298-306, 2014. 
[36] N. Elkum, F. Alkayal, F. Noronha et al., "Vitamin D insufficiency in Arabs and South Asians positively associates with polymorphisms in GC and CYP2R1 genes," PLoS ONE, vol. 9, no. 11, Article ID el13102, 2014.

[37] R. J. Strawbridge, A. Deleskog, O. McLeod et al., "A serum 25-hydroxyvitamin D concentration-associated genetic variant in DHCR7 interacts with type 2 diabetes status to influence subclinical atherosclerosis (measured by carotid intima-media thickness)," Diabetologia, vol. 57, no. 6, pp. 1159-1172, 2014.

[38] C. L. Wagner, S. N. Taylor, A. Dawodu, D. D. Johnson, and B. W. Hollis, "Vitamin D and its role during pregnancy in attaining optimal health of mother and fetus," Nutrients, vol. 4, no. 3, pp. 208-230, 2012.

[39] J. A. Tamblyn, M. Hewison, C. L. Wagner, J. N. Bulmer, and M. D. Kilby, "Immunological role of vitamin D at the maternal-fetal interface," Journal of Endocrinology, vol. 224, no. 3, pp. R107R121, 2015.

[40] C. E. Hayes, S. L. Hubler, J. R. Moore, L. E. Barta, C. E. Praska, and F. E. Nashold, "Vitamin D actions on $\mathrm{CD}^{+} \mathrm{T}$ cells in autoimmune disease," Frontiers in Immunology, vol. 6, article 100, 2015.

[41] T. L. Van Belle, A. Vanherwegen, D. Feyaerts et al., "1,25dihydroxyvitamin $\mathrm{D}_{3}$ and its analog TX527 promote a stable regulatory $\mathrm{T}$ cell phenotype in $\mathrm{T}$ cells from type 1 diabetes patients," PLoS ONE, vol. 9, no. 10, Article ID e109194, 2014.

[42] C. Ning, L. Liu, G. Lv et al., "Lipid metabolism and inflammation modulated by Vitamin D in liver of diabetic rats," Lipids in Health and Disease, vol. 14, article 31, 2015.

[43] L. Mao, F. Ji, Y. Liu, W. Zhang, and X. Ma, "Calcitriol plays a protective role in diabetic nephropathy through antiinflammatory effects," International Journal of Clinical and Experimental Medicine, vol. 7, no. 12, pp. 5437-5444, 2014.

[44] C.-K. Cheon, H.-K. Nam, K.-H. Lee, S. Y. Kim, J. S. Song, and C. Kim, "Vitamin D receptor gene polymorphisms and type 1 diabetes mellitus in a Korean population," Pediatrics International, 2015.

[45] Y. Morán-Auth, M. Penna-Martinez, and K. Badenhoop, "VDR FokI polymorphism is associated with a reduced T-helper cell population under vitamin $\mathrm{D}$ stimulation in type 1 diabetes patients," The Journal of Steroid Biochemistry and Molecular Biology, vol. 148, pp. 184-186, 2015.

[46] Z. Liu, L. Liu, X. Chen, W. He, and X. Yu, "Associations study of vitamin D receptor gene polymorphisms with diabetic microvascular complications: a meta-analysis," Gene, vol. 546, no. 1, pp. 6-10, 2014.

[47] J. De Azevêdo Silva, R. L. Guimarães, L. A. C. Brandão et al., "Vitamin D receptor (VDR) gene polymorphisms and age onset in type 1 diabetes mellitus," Autoimmunity, vol. 46, no. 6, pp. 382-387, 2013.

[48] K. Tizaoui, W. Kaabachi, A. Hamzaoui, and K. Hamzaoui, "Contribution of VDR polymorphisms to type 1 diabetes susceptibility: systematic review of case-control studies and metaanalysis," The Journal of Steroid Biochemistry and Molecular Biology, vol. 143, pp. 240-249, 2014.

[49] M. M. Kamel, S. A. Fouad, O. Salaheldin, A. E.-R. A. A. ElRazek, and A. I. A. El-Fatah, "Impact of vitamin D receptor gene polymorphisms in pathogenesis of Type-1 diabetes mellitus," International Journal of Clinical and Experimental Medicine, vol. 7, no. 12, pp. 5505-5510, 2014.
[50] X. Zhong, Y. Du, Y. Lei, N. Liu, Y. Guo, and T. Pan, "Effects of vitamin D receptor gene polymorphism and clinical characteristics on risk of diabetic retinopathy in Han Chinese type 2 diabetes patients," Gene, vol. 566, no. 2, pp. 212-216, 2015.

[51] B. Frederiksen, E. Liu, J. Romanos et al., "Investigation of the vitamin D receptor gene (VDR) and its interaction with protein tyrosine phosphatase, non-receptor type 2 gene (PTPN2) on risk of islet autoimmunity and type 1 diabetes: the Diabetes Autoimmunity Study in the Young (DAISY)," Journal of Steroid Biochemistry and Molecular Biology, vol. 133, no. 1, pp. 51-57, 2013.

[52] X. Wu, R. C. Davis, T. S. McMillen et al., "Genetic modulation of diabetic nephropathy among mouse strains with Ins2 Akita mutation," Physiological Reports, vol. 2, no. 11, Article ID e12208, 2014.

[53] D. Dutta, S. Choudhuri, S. A. Mondal, S. Mukherjee, and S. Chowdhury, "Urinary albumin: creatinine ratio predicts prediabetes progression to diabetes and reversal to normoglycemia: role of associated insulin resistance, inflammatory cytokines and low vitamin D," Journal of Diabetes, vol. 6, no. 4, pp. 316322, 2014.

[54] A. M. H. Mackawy and M. E. H. Badawi, "Association of vitamin $\mathrm{D}$ and vitamin $\mathrm{D}$ receptor gene polymorphisms with chronic inflammation, insulin resistance and metabolic syndrome components in type 2 diabetic Egyptian patients," Meta Gene, vol. 2, pp. 540-556, 2014.

[55] G. Zoppini, A. Galletti, G. Targher et al., "Lower levels of 25hydroxyvitamin D3 are associated with a higher prevalence of microvascular complications in patients with type 2 diabetes," BMJ Open Diabetes Research \& Care, vol. 3, no. 1, Article ID e000058, 2015.

[56] R. M. Sánchez-Hernández, C. García-Cantón, D. L. Lorenzo et al., "The specific relationship between vitamin D deficiency and diabetic nephropathy among patients with advanced chronic kidney disease: a cross-sectional study in Gran Canaria, Spain," Clinical Nephrology, vol. 83, no. 04, pp. 218-224, 2015.

[57] N. Shimo, T. Yasuda, H. Kaneto et al., "Vitamin D deficiency is significantly associated with retinopathy in young Japanese type 1 diabetic patients," Diabetes Research and Clinical Practice, vol. 106, no. 2, pp. e41-e43, 2014.

[58] S. Bonakdaran and N. Shoeibi, "Is there any correlation between vitamin D insufficiency and diabetic retinopathy?" International Journal of Ophthalmology, vol. 8, no. 2, pp. 326-331, 2015.

[59] X.-L. Zhang, Y.-F. Guo, Z.-X. Song, and M. Zhou, "Vitamin D prevents podocyte injury via regulation of macrophage M1/M2 phenotype in diabetic nephropathy rats," Endocrinology, vol. 155, no. 12, pp. 4939-4950, 2014.

[60] Y. Tian, G. Lv, Y. Yang et al., "Effects of vitamin D on renal fibrosis in diabetic nephropathy model rats," International Journal of Clinical and Experimental Pathology, vol. 7, no. 6, pp. 3028-3037, 2014.

[61] S. Goto, H. Fujii, K. Kono et al., "22-oxacalcitriol attenuates bone loss in nonobese type 2 diabetes," Bone, vol. 74, pp. 153159, 2015.

[62] R.-H. Chen, X.-H. Zhao, Z. Gu et al., "Serum levels of 25hydroxyvitamin $\mathrm{D}$ are associated with cognitive impairment in type 2 diabetic adults," Endocrine, vol. 45, no. 2, pp. 319-324, 2014.

[63] G. Muscogiuri, V. Nuzzo, A. Gatti et al., "Hypovitaminosis D: a novel risk factor for coronary heart disease in type 2 diabetes?" Endocrine, pp. 1-6, 2015. 
[64] A. E. Riek, J. Oh, I. Darwech, C. E. Moynihan, R. R. Bruchas, and C. Bernal-Mizrachi, "25(OH) vitamin D suppresses macrophage adhesion and migration by downregulation of ER stress and scavenger receptor A1 in type 2 diabetes," Journal of Steroid Biochemistry and Molecular Biology, vol. 144, pp. 172-179, 2014.

[65] W. Zhou and S. D. Ye, "Relationship between serum 25hydroxyvitamin $\mathrm{D}$ and lower extremity arterial disease in type 2 diabetes mellitus patients and the analysis of the intervention of vitamin D," Journal of Diabetes Research, vol. 2015, Article ID 815949, 6 pages, 2015.

[66] B. Schöttker and H. Brenner, "Vitamin D as a resilience factor, helpful for survival of potentially fatal conditions: a hypothesis emerging from recent findings of the ESTHER cohort study and the CHANCES consortium," Nutrients, vol. 7, no. 5, pp. 32643278, 2015.

[67] R. Chowdhury, S. Kunutsor, A. Vitezova et al., "Vitamin D and risk of cause specific death: systematic review and meta-analysis of observational cohort and randomised intervention studies," The BMJ, vol. 348, article g1903, 2014.

[68] S. Afzal, P. Brondum-Jacobsen, S. E. Bojesen, and B. G. Nordestgaard, "Genetically low vitamin D concentrations and increased mortality: mendelian randomisation analysis in three large cohorts," British Medical Journal, vol. 349, Article ID g6330, 2014.

[69] H. M. Lee, M. Liu, K. Lee, Y. Luo, and N. D. Wong, "Does low vitamin $\mathrm{D}$ amplify the association of COPD with total and cardiovascular disease mortality?" Clinical Cardiology, vol. 37, no. 8, pp. 473-478, 2014.

[70] T. Skaaby, L. L. N. Husemoen, B. H. Thuesen et al., "Vitamin D status and chronic obstructive pulmonary disease: a prospective general population study," PloS ONE, vol. 9, no. 3, Article ID e90654, 2014.

[71] V. Andre's, "Vitamin D puts the brakes on angiotensin IIinduced oxidative stress and vascular smooth muscle cell senescence," Atherosclerosis, vol. 236, no. 2, pp. 444-447, 2014.

[72] J. Oh, A. Riek, I. Darwech et al., "Deletion of macrophage vitamin d receptor promotes insulin resistance and monocyte cholesterol transport to accelerate atherosclerosis in mice," Cell Reports, vol. 10, no. 11, pp. 1872-1886, 2015.

[73] I. Mozos and O. Marginean, "Links between vitamin D deficiency and cardiovascular diseases," BioMed Research International, vol. 2015, Article ID 109275, 12 pages, 2015.

[74] A. R. Menezes, M. C. Lamb, C. J. Lavie, and J. J. DiNicolantonio, "Vitamin D and atherosclerosis," Current Opinion in Cardiology, vol. 29, no. 6, pp. 571-577, 2014.

[75] T. Skaaby, L. L. N. Husemoen, T. Martinussen et al., "Vitamin D status, filaggrin genotype, and cardiovascular risk factors: a mendelian randomization approach," PLoS ONE, vol. 8, no. 2, Article ID e57647, 2013.

[76] T. Skaaby, L. L. N. Husemoen, C. Pisinger et al., "Vitamin D status and changes in cardiovascular risk factors: a prospective study of a general population," Cardiology (Switzerland), vol. 123, no. 1, pp. 62-70, 2012.

[77] A. Lertratanakul, P. Wu, A. Dyer et al., "25-hydroxyvitamin D and cardiovascular disease in patients with systemic lupus erythematosus: data from a large international inception cohort," Arthritis Care \& Research, vol. 66, no. 8, pp. 1167-1176, 2014.

[78] A. Vitezova, M. C. Zillikens, T. T. VanHerpt et al., "Vitamin D status and metabolic syndrome in the elderly: the Rotterdam study," European Journal of Endocrinology, vol. 172, no. 3, pp. 327-335, 2015.
[79] S. Lai, B. Coppola, M. Dimko et al., "Vitamin D deficiency, insulin resistance, and ventricular hypertrophy in the early stages of chronic kidney disease," Renal Failure, vol. 36, no. 1, pp. 58-64, 2014.

[80] L. Perna, B. Schöttker, B. Holleczek, and H. Brenner, "Serum 25-hydroxyvitamin D and incidence of fatal and nonfatal cardiovascular events: a prospective study with repeated measurements," Journal of Clinical Endocrinology and Metabolism, vol. 98, no. 12, pp. 4908-4915, 2013.

[81] P. F. Schnatz, M. Nudy, X. Jiang, J. E. Demko, and S. E. Appt, "Vitamin D deficiency and cardiovascular disease in postmenopausal women: contributions from human and nonhuman primate studies," Menopause, vol. 22, no. 5, pp. 554-563, 2015.

[82] A. Vitezova, N. S. Cartolano, J. Heeringa et al., "Vitamin D and the risk of atrial fibrillation-the rotterdam study," PLOS ONE, vol. 10, no. 5, Article ID e0125161, 2015.

[83] C. McGreevy, M. Barry, C. Davenport et al., "The effect of vitamin D supplementation on arterial stiffness in an elderly community-based population," Journal of the American Society of Hypertension, vol. 9, no. 3, pp. 176-183, 2015.

[84] D. Martins, Y. Meng, N. Tareen et al., "The effect of short term vitamin $\mathrm{d}$ supplementation on the inflammatory and oxidative mediators of arterial stiffness," Health, vol. 6, no. 12, pp. 15031511, 2014.

[85] O.-H. Ryu, W. Chung, S. Lee, K.-S. Hong, M.-G. Choi, and H. J. Yoo, "The effect of high-dose vitamin D supplementation on insulin resistance and arterial stiffness in patients with type 2 diabetes," Korean Journal of Internal Medicine, vol. 29, no. 5, pp. 620-629, 2014.

[86] T. Skaaby, L. L. N. Husemoen, C. Pisinger et al., "Vitamin $\mathrm{D}$ status and incident cardiovascular disease and all-cause mortality: a general population study," Endocrine, vol. 43, no. 3, pp. 618-625, 2013.

[87] A. Gupta, S. Prabhakar, M. Modi, S. K. Bhadada, V. Lal, and D. Khurana, "Vitamin D status and risk of ischemic stroke in North Indian patients," Indian Journal of Endocrinology and Metabolism, vol. 18, no. 5, pp. 721-725, 2014.

[88] A. Roy, R. Lakshmy, M. Tarik, N. Tandon, K. S. Reddy, and D. Prabhakaran, "Independent association of severe vitamin D deficiency as a risk of acute myocardial infarction in Indians," Indian Heart Journal, vol. 67, no. 1, pp. 27-32, 2015.

[89] P. L. Lutsey, E. D. Michos, J. R. Misialek et al., "Race and vitamin $\mathrm{D}$ binding protein gene polymorphisms modify the association of 25-hydroxyvitamin D and incident heart failure: the ARIC (Atherosclerosis Risk in Communities) study," Heart Failure, vol. 3, no. 5, pp. 347-356, 2015.

[90] K. S. Vimaleswaran, A. Cavadino, D. J. Berry et al., "Association of vitamin D status with arterial blood pressure and hypertension risk: a mendelian randomisation study," The Lancet Diabetes \& Endocrinology, vol. 2, no. 9, pp. 719-729, 2014.

[91] S. Pilz, M. Gaksch, K. Kienreich et al., "Effects of vitamin D on blood pressure and cardiovascular risk factors: a randomized controlled trial," Hypertension, vol. 65, no. 6, pp. 1195-1201, 2015.

[92] D. Rendina, R. Ippolito, L. D’Elia et al., "Hypovitaminosis D and organ damage in patients with arterial hypertension: a multicenter double blind randomised controlled trial of cholecalciferol supplementation (HYPODD): study design, clinical procedures and treatment protocol," High Blood Pressure \& Cardiovascular Prevention, vol. 22, no. 2, pp. 135-142, 2015. 
[93] P. F. Schnatz and J. E. Manson, "Vitamin D and cardiovascular disease: an appraisal of the evidence," Clinical Chemistry, vol. 60, no. 4, pp. 600-609, 2014.

[94] S. K. Kunutsor, S. Burgess, P. B. Munroe, and H. Khan, "Vitamin D and high blood pressure: causal association or epiphenomenon?" European Journal of Epidemiology, vol. 29, no. 1, pp. 1-14, 2014.

[95] M. Sunbul, M. Bozbay, C. Mammadov et al., "Effect of vitamin $\mathrm{D}$ deficiency and supplementation on myocardial deformation parameters and epicardial fat thickness in patients free of cardiovascular risk," The International Journal of Cardiovascular Imaging, vol. 31, no. 4, pp. 765-772, 2015.

[96] S. Bonakdaran, A. F. Nejad, V. Abdol-Reza, A. Hatefi, and M. Shakeri, "Impact of oral 1,25-dihydroxy vitamin D (calcitriol) replacement therapy on coronary artery risk factors in type 2 diabetic patients," Endocrine, Metabolic \& Immune Disorders Drug Targets, vol. 13, no. 4, pp. 295-300, 2013.

[97] K. Tomaino, K. M. Romero, C. L. Robinson et al., "Association between serum 25-hydroxy vitamin D levels and blood pressure among adolescents in two resource-limited settings in Peru," American Journal of Hypertension, vol. 28, no. 8, pp. 1017-1023, 2015.

[98] H. Mozaffari-Khosravi, S. Loloei, M.-R. Mirjalili, and K. Barzegar, "The effect of vitamin D supplementation on blood pressure in patients with elevated blood pressure and vitamin D deficiency: a randomized, double-blind, placebo-controlled trial," Blood Pressure Monitoring, vol. 20, no. 2, pp. 83-91, 2015.

[99] K. M. Gurses, L. Tokgozoglu, M. U. Yalcin et al., "Markers of subclinical atherosclerosis in premenopausal women with vitamin D deficiency and effect of vitamin D replacement," Atherosclerosis, vol. 237, no. 2, pp. 784-789, 2014.

[100] A. B. Robinson, V. Tangpricha, E. Yow, R. Gurion, L. E. Schanberg, and G. A. McComsey, "Vitamin D status is a determinant of atorvastatin effect on carotid intima medial thickening progression rate in children with lupus: an Atherosclerosis Prevention in Pediatric Lupus Erythematosus (APPLE) substudy," Lupus Science \& Medicine, vol. 1, no. 1, Article ID e000037, 2014.

[101] S. Satilmis, O. Celik, I. Biyik et al., "Association between serum vitamin D levels and subclinical coronary atherosclerosis and plaque burden/composition in young adult population," Bosnian Journal of Basic Medical Sciences, vol. 15, no. 1, pp. 6772, 2015.

[102] A. Alyami, M. J. Soares, J. L. Sherriff, and J. C. Mamo, "Vitamin D \& endothelial function," The Indian Journal of Medical Research, vol. 140, no. 4, pp. 483-490, 2014.

[103] J. S. Ho, J. J. Cannaday, C. E. Barlow, D. B. Reinhardt, W. A. Wade, and J. R. Ellis, "Low 25-OH vitamin D levels are not associated with coronary artery calcium or obstructive stenoses," Coronary Artery Disease, vol. 26, no. 6, pp. 521-525, 2015.

[104] J. Y. Liew, S. R. Sasha, P. J. Ngu et al., "Circulating vitamin D levels are associated with the presence and severity of coronary artery disease but not peripheral arterial disease in patients undergoing coronary angiography," Nutrition, Metabolism and Cardiovascular Diseases, vol. 25, no. 3, pp. 274-279, 2015.

[105] R. Malik, E. C. Aneni, L. Roberson et al., "Measuring coronary artery calcification: is serum vitamin D relevant?" Atherosclerosis, vol. 237, no. 2, pp. 734-738, 2014.

[106] K. Winckler, L. Tarnow, L. L. Christensen et al., "Vitamin D, carotid intima-media thickness and bone structure in patients with type 2 diabetes," Endocrine Connections, vol. 4, no. 2, pp. 128-135, 2015.
[107] J.-Y. Jung, B.-R. Koh, C.-B. Bae, H.-A. Kim, and C.-H. Suh, "Carotid subclinical atherosclerosis is associated with disease activity but not vitamin D in Korean systemic lupus erythematosus," Lupus, vol. 23, no. 14, pp. 1517-1522, 2014.

[108] A. N. Kiani, H. Fang, L. S. Magder, and M. Petri, "Vitamin $\mathrm{D}$ deficiency does not predict progression of coronary artery calcium, carotid intima-media thickness or high-sensitivity Creactive protein in systemic lupus erythematosus," Rheumatology, vol. 52, no. 11, Article ID ket271, pp. 2071-2076, 2013.

[109] J. Portilla, Ó. Moreno-Pérez, C. Serna-Candel et al., "Vitamin $\mathrm{D}$ insufficiency and subclinical atherosclerosis in non-diabetic males living with HIV," Journal of the International AIDS Society, vol. 17, Article ID 18945, 2014.

[110] H. Mangge, S. Zelzer, A. Meinitzer et al., "25OH-vitamin D3 levels in obesity and metabolic syndrome-unaltered in young and not correlated to carotid IMT in all ages," Current Pharmaceutical Design, vol. 21, no. 17, pp. 2243-2249, 2015.

[111] M. D. Walker, E. Cong, A. Kepley et al., "Association between serum 25-hydroxyvitamin D level and subclinical cardiovascular disease in primary hyperparathyroidism," Journal of Clinical Endocrinology and Metabolism, vol. 99, no. 2, pp. 671-680, 2014.

[112] V. Carnevale, R. Minonne, A. De Matthaeis et al., "Carotid intima-media thickness is not associated with vitamin $\mathrm{D}$ and PTH levels in patients admitted to an Internal Medicine Department," Endocrine, vol. 47, no. 3, pp. 833-838, 2014.

[113] R.-H. Chen, X.-Z. Jiang, Q. Jiang et al., "Correlations between serum levels of 25-hydroxyvitamin D and carotid atherosclerosis in patients with type 2 diabetes in Shanghai," Annales d'Endocrinologie, vol. 75, no. 4, pp. 206-212, 2014.

[114] J. Orgaz-Molina, C. Magro-Checa, J. L. Rosales-Alexander et al., "Vitamin D insufficiency is associated with higher carotid intima-media thickness in psoriatic patients," European Journal of Dermatology, vol. 24, no. 1, pp. 53-62, 2014.

[115] Y. Hao, X. Ma, Y. Luo et al., "Inverse association of serum vitamin $\mathrm{D}$ in relation to carotid intima-media thickness in Chinese postmenopausal women," PLoS ONE, vol. 10, no. 3, Article ID e0122803, 2015.

[116] M. Juonala, A. Voipio, K. Pahkala et al., "Childhood 25$\mathrm{OH}$ vitamin $\mathrm{D}$ levels and carotid intima-media thickness in adulthood: the cardiovascular risk in young Finns study," The Journal of Clinical Endocrinology \& Metabolism, vol. 100, no. 4, pp. 1469-1476, 2015.

[117] S. C. Van Dijk, E. Sohl, C. Oudshoorn et al., "Non-linear associations between serum 25-OH vitamin $\mathrm{D}$ and indices of arterial stiffness and arteriosclerosis in an older population," Age and Ageing, vol. 44, no. 1, pp. 136-142, 2015.

[118] G. Y. Kalkan, M. Gür, N. Y. Koyunsever et al., "Serum 25hydroxyvitamin D level and aortic intima-media thickness in patients without clinical manifestation of atherosclerotic cardiovascular disease," Journal of Clinical Laboratory Analysis, vol. 29, no. 4, pp. 305-311, 2015.

[119] K. Gholami, A. H. Talasaz, T. Entezari-Maleki et al., “The effect of high-dose vitamin D3 on soluble P-selectin and hs-CRP level in patients with venous thromboembolism: a randomized clinical trial," Clinical and Applied Thrombosis/Hemostasis, 2015.

[120] T. Entezari-Maleki, A. H. Talasaz, M. Salarifar et al., "Plasma vitamin D status and its correlation with risk factors of thrombosis, P-selectin and hs-CRP level in patients with venous thromboembolism; the first study of iranian population," Iranian Journal of Pharmaceutical Research, vol. 13, no. 1, pp. 319327, 2014. 
[121] A. R. Folsom, N. S. Roetker, W. D. Rosamond et al., "Serum 25hydroxyvitamin D and risk of venous thromboembolism: the Atherosclerosis Risk in Communities (ARIC) Study," Journal of Thrombosis and Haemostasis, vol. 12, no. 9, pp. 1455-1460, 2014.

[122] P. Ameri, M. Canepa, P. Fabbi et al., "Vitamin D modulates the association of circulating insulin-like growth factor-1 with carotid artery intima-media thickness," Atherosclerosis, vol. 236, no. 2, pp. 418-425, 2014.

[123] H. Y. Park, J. H. Kim, S. Bae, Y. Y. Choi, J. Y. Park, and Y.-C. Hong, "Interaction effect of serum 25-hydroxyvitamin D levels and CYP1A1, CYP1B1 polymorphisms on blood pressure in an elderly population," Journal of Hypertension, vol. 33, no. 1, pp. 69-76, 2015.

[124] M. A. Abu El Maaty, S. I. Hassanein, H. M. Sleem, and M. Z. Gad, "Effect of polymorphisms in the NADSYN1/DHCR7 locus (rs12785878 and rs1790349) on plasma 25-hydroxyvitamin D levels and coronary artery disease incidence," Journal of Nutrigenetics and Nutrigenomics, vol. 6, no. 6, pp. 327-335, 2014. 


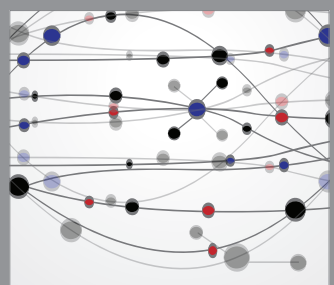

The Scientific World Journal
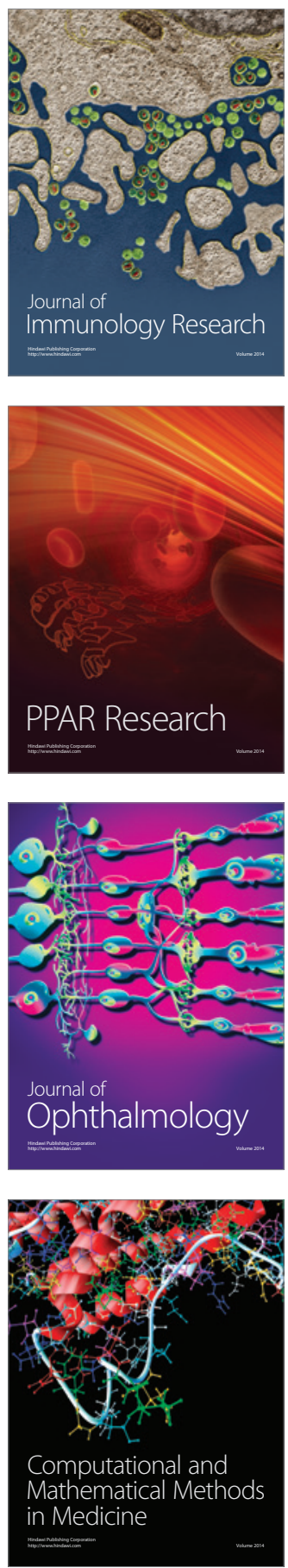

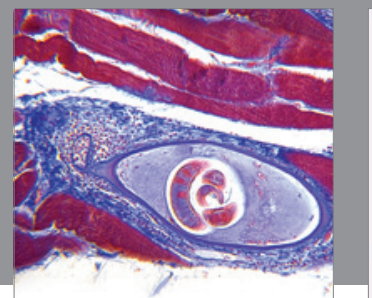

Gastroenterology

Research and Practice
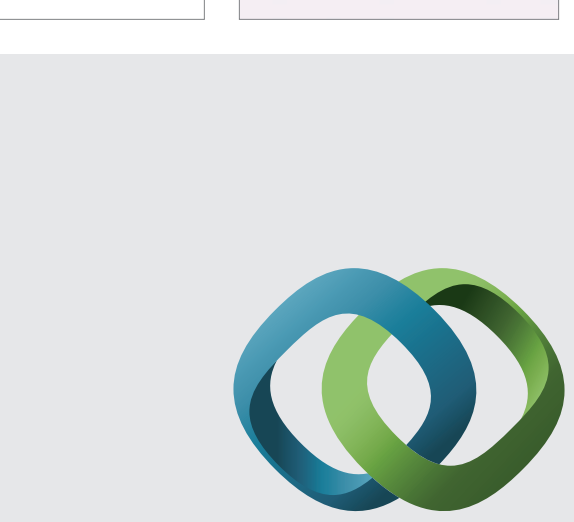

\section{Hindawi}

Submit your manuscripts at

http://www.hindawi.com
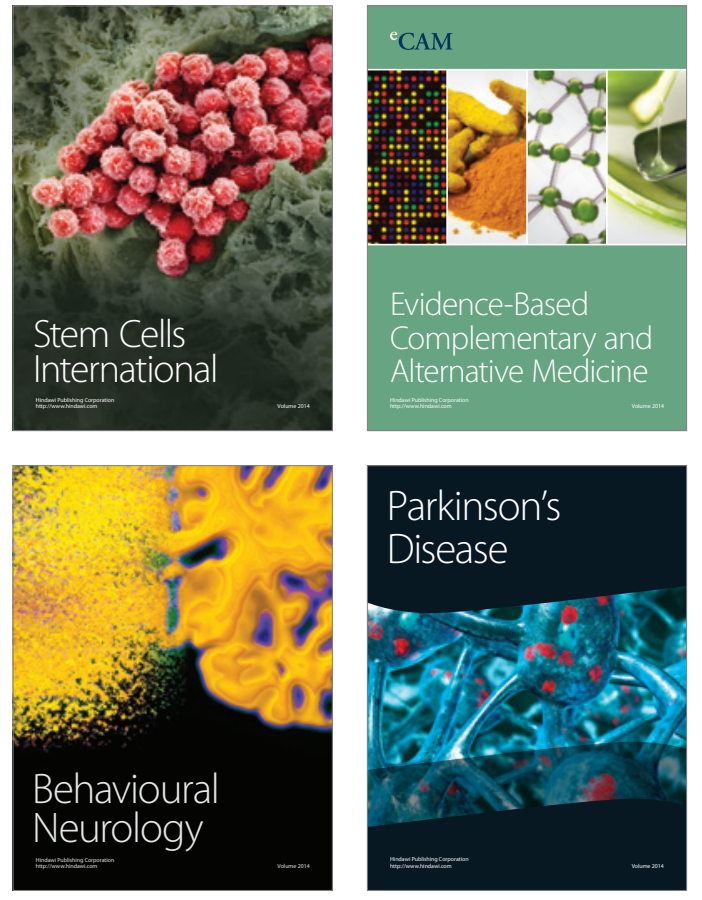
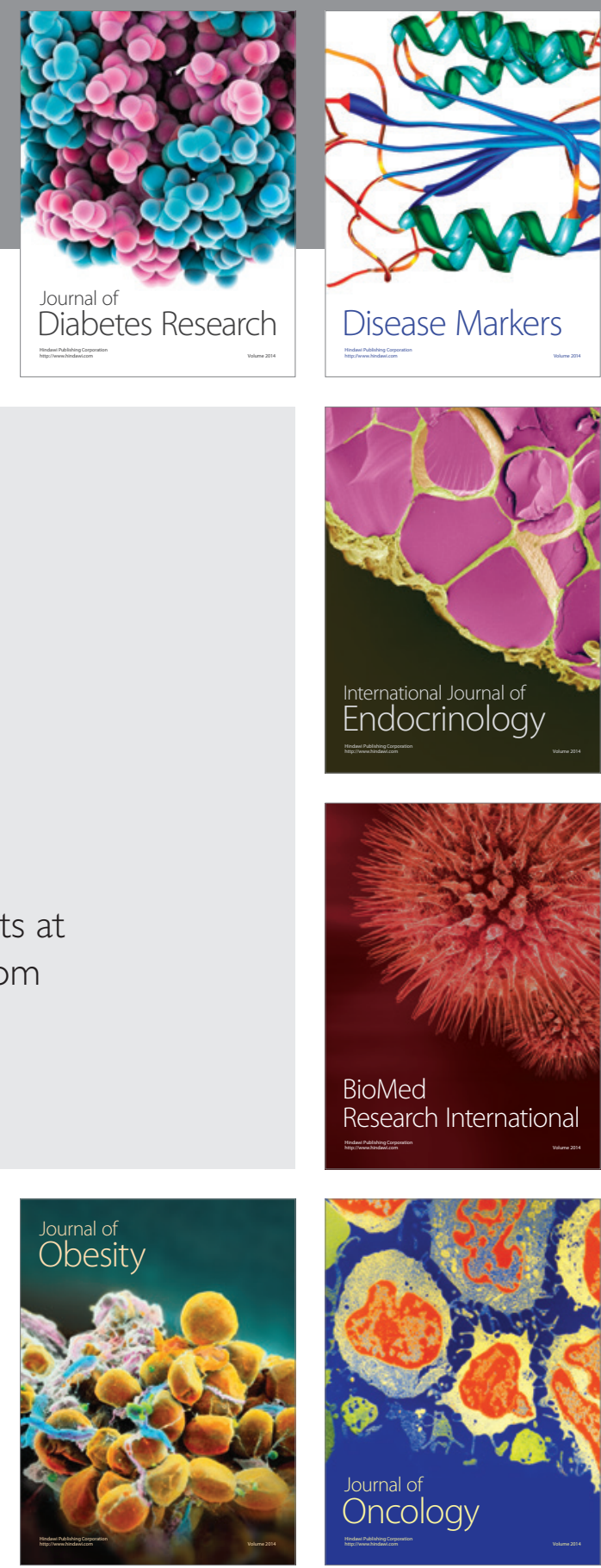

Disease Markers
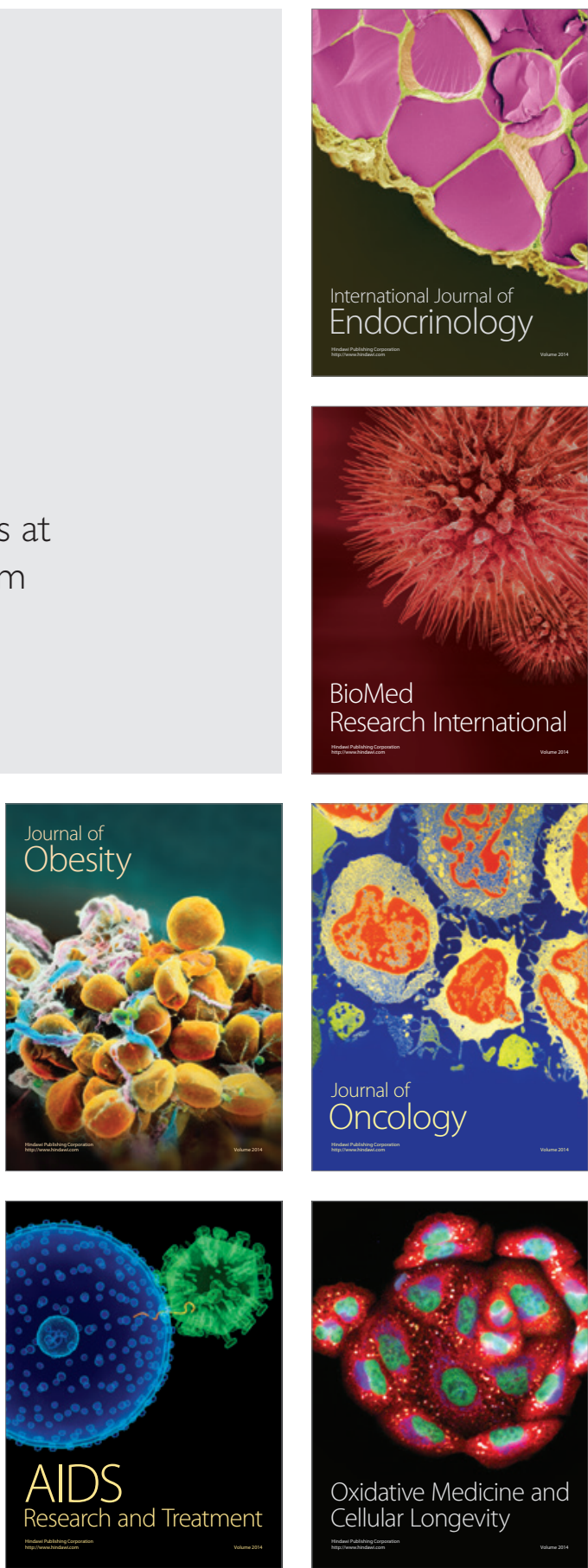